\title{
Prevalence of Pharmaceuticals in Surface Water Samples in Ghana
}

\author{
David Azanu, ${ }^{1}$ David Adu-Poku $\mathbb{D}^{2},{ }^{2}$ Selina Ama Saah, ${ }^{2}$ and William Ofori Appaw ${ }^{3}$ \\ ${ }^{1}$ Department of Laboratory Technology, Kumasi Technical University, Kumasi, Ghana \\ ${ }^{2}$ Department of Chemical Sciences, University of Energy and Natural Resources, Sunyani, Ghana \\ ${ }^{3}$ Department of Food Science and Technology, Kwame Nkrumah University of Science and Technology, Kumasi, Ghana \\ Correspondence should be addressed to David Adu-Poku; david.adu-poku@uenr.edu.gh
}

Received 20 September 2021; Accepted 27 November 2021; Published 17 December 2021

Academic Editor: Zenilda Cardeal

Copyright (C) 2021 David Azanu et al. This is an open access article distributed under the Creative Commons Attribution License, which permits unrestricted use, distribution, and reproduction in any medium, provided the original work is properly cited.

\begin{abstract}
Pharmaceuticals, among the emerging contaminants, are pseudopersistent and recently of serious concern due to universal use, toxicity, and resistance development at low concentrations. This study was aimed at assessing the prevalence and risk of eight pharmaceuticals in surface water used for vegetable irrigation in Ghana's Kumasi and Sunyani metropolises, which are influenced by hospitals, sewage treatment facilities, and market effluents. Samples were concentrated via solid-phase extraction (SPE) while liquid chromatography was used to identify and quantify the analytes. Ibuprofen, acetaminophen, and diclofenac were the detected analgesics in this study, with concentrations stretching from below detection limit (not detected) to $319.0 \mathrm{ng} / \mathrm{L}$, while amoxicillin, trimethoprim, and cefuroxime were the detected antibiotics with a concentration range of no detection to $840.0 \mathrm{ng} / \mathrm{L}$. Based on the available long-term data, an environmental risk assessment was conducted. Because of the presence of ibuprofen, the lowest trophic level and fish were shown to be at risk. The estimated risk quotient values for antibiotics resistance were above 1 for all the antibiotics investigated in surface water impacted by the wastewater of hospitals and pharmaceutical companies' except surface water impacted by sewage treatment plants (STPs) and market wastewater. The existence of these pharmaceuticals in surface water does not only point to a general concern for the environment but also a potential health risk on humans and other lives as a result of their impact on drinking water and vegetable production in Ghana.
\end{abstract}

\section{Introduction}

The frequent detection of pharmaceutical residues in different sections of the environment is becoming an increasing cause of resistance and toxicity. The new Global Antimicrobial Resistance and Use Surveillance System report on antibiotics of the World Health Organization confirmed the widespread occurrence of antimicrobial resistance (AMR) across different countries [1]. Though the development of AMR is a natural evolutionary process for microorganisms, multiple studies have established cross-sectional relationships between antibiotic use and resistance [2-5]. The selective pressure caused by the extensive utilization of antimicrobials has been associated with accelerated AMR development. In the past two decades, the increased use of antibiotics outside the developed countries has led to higher global consumption of antibiotics [6]. This suggests that the direct and indirect effect of AMR will be grievous on low- and middle-income countries, such as Ghana, with constrained infrastructure, and human and financial resources to sufficiently offset drug-resistant epidemics.

The detection of antibiotic and analgesic residues in various aquatic compartments including municipal sewage, hospital sewage, groundwater, surface water, and drinking water at various concentrations [7-9] has been widely reported. While several of such reviews have highlighted aquatic monitoring in the European Union [10], the USA [11], and China [12], not much is known in the literature regarding the problem in sub-Saharan Africa [13]. Again, the lack of a universal view of what happens when these pharmaceuticals are released into the environment has lately become topical [14]. Although safety and toxicological studies have commonly provided some exposure to the side effects of these pharmaceuticals on human and animal health, the potential environmental consequences are less understood. 
In Ghana, no policy or guidelines exist for the use of antibiotics in animals, and existing regulations meant to restrict antibiotic prescriptions for human use such as the Standard Treatment Guidelines (STG), Essential Medicines List (EML), and the National Health Insurance Scheme (NHIS) medicines list are not being adhered to [15]. Antibiotics are widely prescribed (with $>40 \%$ of outpatient prescriptions containing antibiotics) and dispensed by unauthorized persons [16]. The story, arguably, may not be different from other classes of pharmaceuticals such as analgesics, antimalarial, antipyretics, antiseptics, and mood stabilizers.

According to Lerbech et al. [17], pharmaceutical products are widely available to the public from a lot of channels, such as hospitals and pharmacies, medical stalls, drug shops, and peddlers, despite severe restrictions. This widespread access has resulted in inappropriate use with residual consequences on the environment.

Recent research has also shown that edible crops such as tomatoes, cucumbers, carrots, and lettuce may absorb pharmacological chemicals from their growing environment through their roots $[18,19]$. Through the food chain, bioaccumulation, and biomagnification, human and animal health may be endangered.

The activity of pharmaceuticals in water, soils, and plants is yet unknown and is very speculative. Biodegradation data analysis is also problematic due to the fact that kinetics is largely unknown [13].

Available literature has it that the levels of pharmaceuticals in surface and groundwater sources influenced by wastewater discharges are normally well below $0.1 \mu \mathrm{g} / \mathrm{l}$ (or $100 \mathrm{ng} / \mathrm{l})$ while in treated drinking water are typically less than $0.05 \mu \mathrm{g} / \mathrm{l}$ (or $50 \mathrm{ng} / \mathrm{l}$ ), an indication of no risk to human health [20]. That notwithstanding, the existing knowledge gaps linked to risks associated with long-term exposure to low concentrations of pharmaceuticals and the combined effects of blends of pharmaceuticals should be of concern [21]. Furthermore, because antimicrobial drug resistance is such an essential element of public health, we calculated the risk quotients (RQs) for antibiotic resistance in diverse water bodies.

This study, therefore, focused on the prevalence and risk assessment of 8 pharmaceuticals (chemical structures and physicochemical parameters are shown in Table 1) in surface water used for vegetable irrigation, which is under the influence of hospitals, sewage treatment plants, and market effluents in Kumasi and Sunyani metropolises of Ghana.

\section{Materials and Methods}

2.1. Chemicals and Reagents. Sigma-Aldrich (Dorset, UK) supplied tramadol hydrochloride (CAS \#: 36282-47-0, >99 percent pure) and diazepam (CAS \#:439-14-5, 98 percent pure), whereas Fluka (Steinheim, Germany) supplied amoxicillin trihydrate (CAS \#: 267-87-780, 98 percent pure). Acetaminophen, ibuprofen, cefuroxime, and penicillin $\mathrm{V}$ were all donated by Phyto-Riker Pharmaceuticals Ltd., Ghana.
Merck supplied HPLC grade methanol (CAS \#: 67-56-1, $>99.9 \%$ pure) and acetonitrile (CAS \#: 75-05-8, >99.9\% pure). Distilled water was bought from KNUST Central Laboratory. Methanol was used to make the stock solutions, which were maintained frozen at $-18 \mathrm{C}$.

2.2. Study Area. This study of pharmaceuticals was carried out in two cities in Ghana, West Africa (Sunyani and Kumasi), each of which has a rapid city growth and development. These cities were selected because studies have revealed that most wastewater is released to drains that discharge untreated into one of the streams flowing through or originating from Kumasi.

Sunyani is in the middle belt of Ghana. It is drained by seven tributaries of the Tano River (Figure 1(a)). These water bodies are located in the districts of Sunyani (stretches across four neighborhoods of the city), Akokora Kwadwo (Sunyani Estate), Agyei (number 2), Nsakonsuano (Nkwabeng North), Aboshyensua (Ministries Area), Danyame, and Tuasua (Sunyani Estate).

Drainage at Kumasi is split into two halves, with $28 \%$ of the area draining to the west that ends up in Offin River. The reminder $78 \%$ drain southward entering into Oda River that is located on a drainage divide, and $28 \%$ of the developed area eventually drain to the west joining the Offin River. About $72 \%$ of the developed area drain to the Oda River in the south of the city. Most streams originate within the administrative boundaries of Kumasi. The only major inflow from outside sources comes from the Sisa and Wiwa rivers, which run towards the north of Kumasi (Figure 1(b)).

In the study city Sunyani, the water samples were collected from Akokora Kwadwo River at a point labeled SP, which receives effluent from the hospitals in the city. The second sampling point, SP2, was from the River Tuasua, which receives wastewater from the main market in the city (Figure 1(a)).

In Kumasi, surface water was sampled from River Wiwi at a point indicated as KP1, which receives effluent from Ahensan waste stabilization ponds (WSPs), and River Oda, which receives effluent from Chirapatre WSPs that was sampled at point KP2. The surface water that receives effluent from pharmaceutical production companies was sampled at points KP3, KP4, and KP5. Subin River was sampled at a point KP6, after receiving wastewater from a hospital denoted Hospital A, while Wiwi River was sampled at point KP7, after receiving wastewater from hospital denoted Hospital B (Figure 1(b)).

2.3. Sampling Procedure. The three sample regions yielded a total of 9 sampling points (Figure 1). Two sampling periods were conducted, one in February and the other in May of the same year. Two replicates of composite water samples were obtained at each sampling station. A total of $1 \mathrm{~L}$ was collected at 30 mins interval from the same spot and placed in $1.5 \mathrm{~L}$ brown HDPE bottles (by pooling $200 \mathrm{~mL}$ aliquots for 5 times) In total, 54 water samples 
TABLE 1: For the pharmaceutical compounds under investigation, chemical structures and relevant physicochemical properties were examined.

\begin{tabular}{|c|c|c|c|c|c|c|c|}
\hline Antibiotic/CAS-Nr & ID & Structure & Molecular formula & MW & Log Kow & $\mathrm{pKa}$ & Solubility $(\mathrm{g} / \mathrm{L})$ \\
\hline $\begin{array}{l}\text { Tramadol } \\
36282-47-0\end{array}$ & TRAM & & $\mathrm{C}_{16} \mathrm{H}_{26} \mathrm{ClNO}_{2}$ & 299.83 & 2.1 & 5.6 & 0.01 \\
\hline $\begin{array}{l}\text { Ibuprofen } \\
15687-27-1\end{array}$ & IBU & & $\mathrm{C}_{13} \mathrm{H}_{18} \mathrm{O}_{2}$ & 206.28 & 3.97 & 5.2 & 0.021 \\
\hline $\begin{array}{l}\text { Acetaminophen } \\
\text { 103-90-2 }\end{array}$ & $\mathrm{ACT}$ & & $\mathrm{C}_{8} \mathrm{H}_{9} \mathrm{NO}_{2}$ & 155.19 & 0.46 & 9.38 & 5.0 \\
\hline $\begin{array}{l}\text { Diazepam } \\
439-14-5\end{array}$ & DIAZ & & $\mathrm{C}_{16} \mathrm{H}_{13} \mathrm{ClN}_{2} \mathrm{O}$ & 284.74 & 2.82 & 3.4 & $<1$ \\
\hline $\begin{array}{l}\text { Trimethoprim } \\
738-70-5\end{array}$ & TRIM & & $\mathrm{C}_{14} \mathrm{H}_{18} \mathrm{~N}_{4} \mathrm{O}_{3}$ & 290.3 & 0.91 & 7.12 & 0.4 \\
\hline $\begin{array}{l}\text { Amoxicillin } \\
\text { 267-87-780 }\end{array}$ & AMX & & $\mathrm{C}_{16} \mathrm{H}_{19} \mathrm{~N}_{3} \mathrm{O}_{5} \mathrm{~S}$ & 365.4 & 0.87 & $2.8,7.2$ & 4.0 \\
\hline $\begin{array}{l}\text { Cefuroxime } \\
55268-75-2\end{array}$ & CEF & & $\mathrm{C}_{16} \mathrm{H}_{16} \mathrm{~N}_{4} \mathrm{O}_{8} \mathrm{~S}$ & 424.4 & -0.16 & 3.15 & 0.145 \\
\hline $\begin{array}{l}\text { Penicillin V } \\
87-08-1\end{array}$ & PENV & & $\mathrm{C}_{16} \mathrm{H}_{18} \mathrm{~N}_{2} \mathrm{O}_{5} \mathrm{~S}$ & 350.4 & & 2.73 & $<1$ \\
\hline
\end{tabular}

were collected and delivered to the CAN Laboratory of Department of Food Science and Technology of KNUST. Filtration was performed on the samples using grade 1 filter paper (Whatman ${ }^{\circledR}$, Merck SA, an affiliate of Merck KGaA, Darmstadt, Germany). These filtered samples were placed into brown HDPE bottles in quantities of $500 \mathrm{~mL}$ each.
2.4. Solid-Phase Extraction of Analytes. The solid-phase extraction procedure described by Azanu et al. [13] was modified and used in this study. Water samples were cleaned up and concentrated on Oasis HLB (hydrophilic-lipophilic balance, $200 \mathrm{mg}$ sorbent, $30 \mathrm{~m}, 6 \mathrm{~cm}^{3}$ ) cartridge supplied by Water Oasis (SPE) (Massachusetts, USA), and $2 \mathrm{~mL} \mathrm{MeOH,}$ thereafter $2 \mathrm{~mL}$ distilled water, was used to condition the 


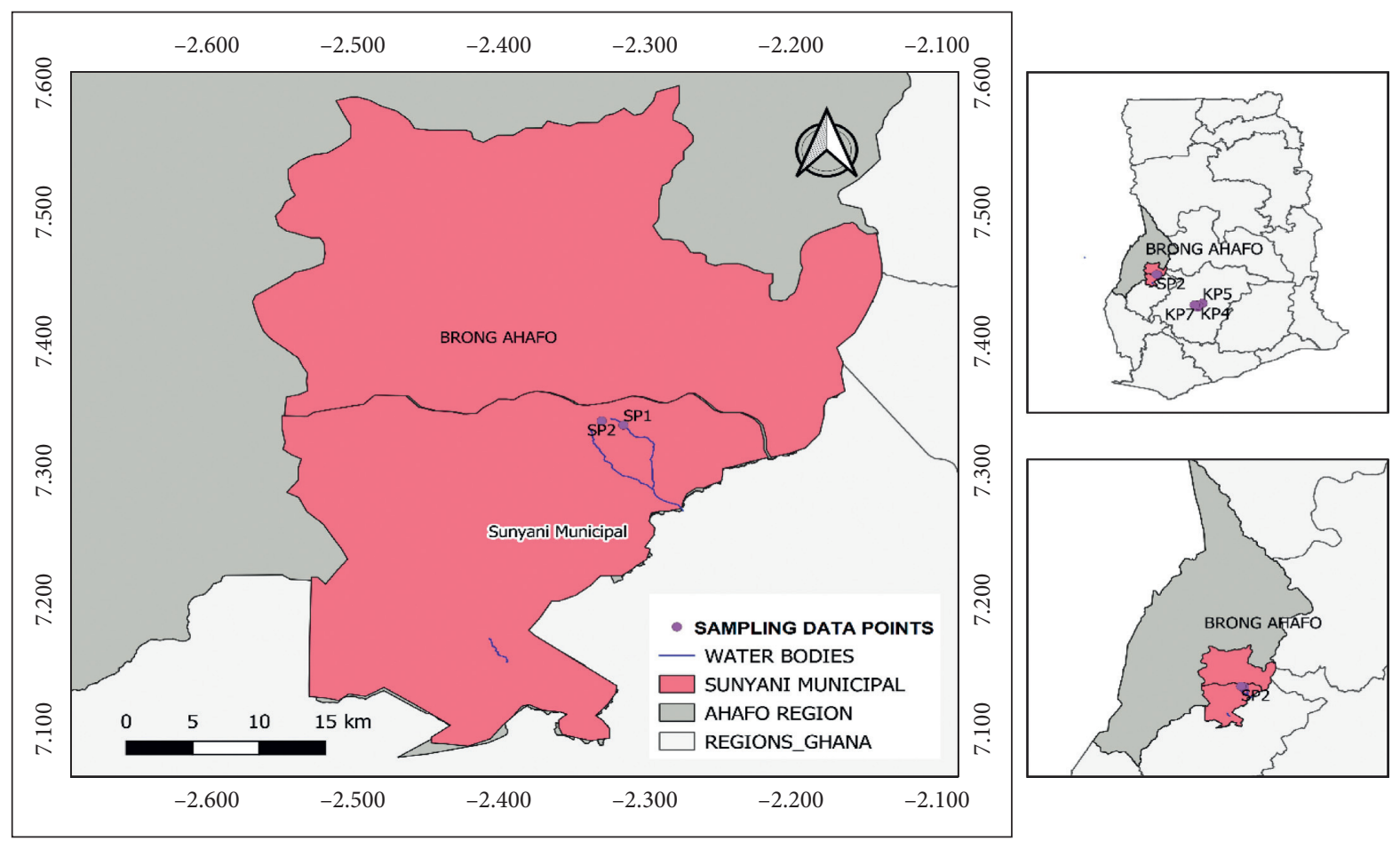

a

(a)
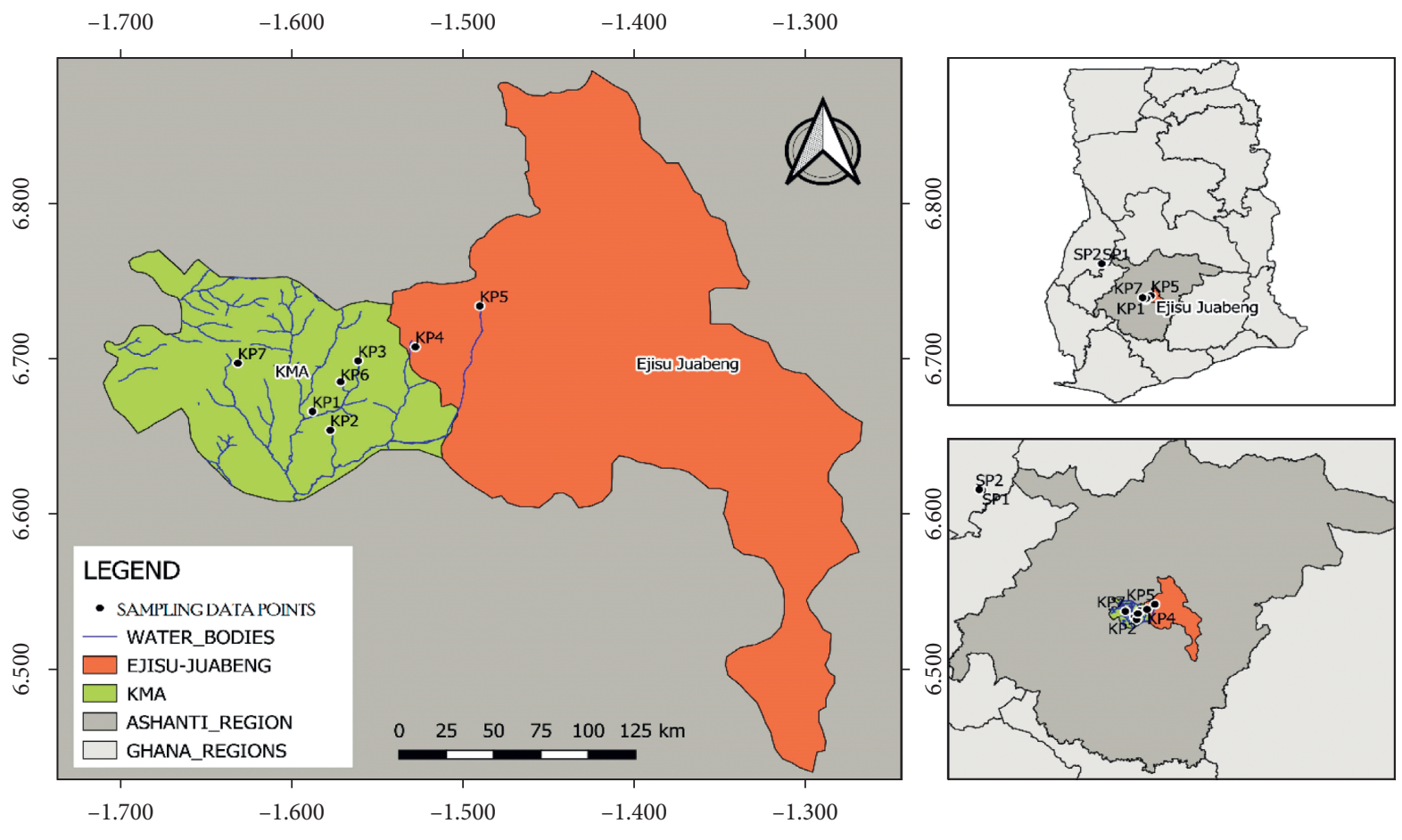

b

(b)

FIgURE 1: A map showing the sampling points at (a) Sunyani metropolis and (b) Kumasi metropolis in Ghana.

SPE cartridge. At a flow rate of $1.5 \mathrm{~mL} / \mathrm{min}, 500 \mathrm{~mL}$ of water samples was put into SPE columns. Dried SPE columns were washed with $3 \mathrm{~mL}$ of $5 \% \mathrm{MeOH}$. After permitting the sorbent under a vacuum to dry for a few minutes, the antibiotics were eluted with $3 \mathrm{~mL} \mathrm{MeOH}$ at a flow rate of about

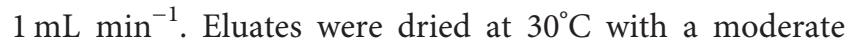


nitrogen flow before being reconstituted in $1 \mathrm{~mL} 1 \% \mathrm{MeOH}$ and injected into brown flatcap HPLC vials for analysis.

2.5. HPLC Analysis. Shraim et al. [22] presented a technique for analyzing pharmaceutical residues in surface water, which was significantly improved and used in this investigation.

2.5.1. Analgesics: Ibuprofen, Tramadol, Diazepam, and Acetaminophen. With a Wave Quest CE4300 UV/Vis Detector, a Cecil-Adept Binary Pump HPLC was used to develop the method for analyzing the analgesics (Cambridge, UK). The chromatographic separation of acetaminophen was achieved using a Zorbax Column $\left(\mathrm{C}_{18}\right.$, $4.6 \mathrm{~mm} \times 250 \mathrm{~mm}, 5 \mu \mathrm{m}$, Agilent Technologies Inc., Palo Alto, CA, USA) while for tramadol, ibuprofen, and diazepam was achieved using a SunFire Column $\left(\mathrm{C}_{18}\right.$, $4.6 \mathrm{~mm} \times 150 \mathrm{~mm}, 5 \mu \mathrm{m}$, Waters, Milford, MA, USA) preceded by a guard column (SunFire, $\mathrm{C}_{18}, 4.6 \mathrm{~mm} \times 10 \mathrm{~mm}$, $5 \mu \mathrm{m}$, Waters, Milford, MA, USA) at $30^{\circ} \mathrm{C}$. The mobile phase used was $40: 60(\mathrm{v} / \mathrm{v}), 0.1 \mathrm{M}$ sodium acetate buffer $(\mathrm{pH}=4)$ : methanol and was pumped at $0.8 \mathrm{~mL} / \mathrm{min}$. A volume of 10 $\mathrm{uL}$ was injected into the HPLC for analysis.

2.5.2. Antibiotics: Amoxicillin, Cefuroxime, Trimethoprim, and Penicillin $V$. A gradient elution using a PerkinElmer Flexar UHPLC with a PDA Plus detector was used for the simultaneous analysis of the analytes. The analytical column used was Waters ${ }^{\circledR}$ uBondapak $(3.9 \mathrm{~mm} \times 300 \mathrm{~mm}, 10 \mu \mathrm{m})$. Water was acidified with $0.1 \%$ formic acid in mobile phase $A$, whereas methanol was acidified with $0.1 \%$ formic acid in mobile phase B. The composition was linearly altered from $99 \%$ A to $85 \%$ in 4 minutes. This gradient was quickly altered to $20 \% \mathrm{~A}$ and $80 \% \mathrm{~B}$ in a 3 -minute linear gradient (from 4 to 7 minutes). This proportion was again linearly changed in $5 \mathrm{~min}$ to $99 \% \mathrm{~A}$ and maintained at this ratio for the remaining 6 minutes. A volume of $10 \mathrm{uL}$ was injected into the HPLC for analysis. A 4-point calibration curve was developed for each analyte across a concentration range of 1.00 to $80.00 \mathrm{~g} / \mathrm{mL}$ for measurement.

2.6. Validation of Analytical Procedure. A 5-point calibration curve was developed for each analyte across a concentration range of 1.0 to $30.00 \mathrm{ng} / \mathrm{L}$ for measurement. Precision and accuracy were determined by spiking a blank sample at low, mid, and high concentrations. The spiked samples were extracted and analyzed as described earlier. The average recoveries varied from 89 to $103 \%$. The coefficients of variation of analyte concentration after 10 injections were below 15\%. The correlation coefficients $\left(r^{2}\right)$ for the calibration curves were all greater than 0.995. Analytical methods were evaluated for precision and accuracy. Limits of detection (LODs) were computed based on the ICH guidelines as $3.3 \mathrm{\sigma} / \mathrm{S}$. LODs for the analytes were $1.0 \mathrm{ng} / \mathrm{L}$ (ibuprofen), $1.3 \mathrm{ng} / \mathrm{L}$ (tramadol), $1.1 \mathrm{ng} / \mathrm{L}$ (diazepam), $1.1 \mathrm{ng} / \mathrm{L}$ (acetaminophen), $1.2 \mathrm{ng} / \mathrm{L}$ (amoxicillin), $1.3 \mathrm{ng} / \mathrm{L}$ (cefuroxime), trimethoprim $(1.0 \mathrm{ng} / \mathrm{L})$, and penicillin $\mathrm{V}$ $(1.2 \mathrm{ng} / \mathrm{L})$.

2.7. Risk Assessment. The risk quotient (RQ) of each antibiotic was computed as the ratio of maximum measured environment concentration (MEC) of an antibiotic to its projected no-effect concentration (PNEC), as prescribed by EMEA [23]. RQ was determined for fish, algae, and daphnid to cater to all levels in the food chain. PNEC data used in this study were obtained from the Ecological Structure-Activity Relationships (ECOSAR) model. PNEC values obtained from the model were multiplied by the assessment factor (AF), which takes care of the inherent uncertainty of measured concentrations. AF values of 100 were used for this study as employed by Leung et al. [24]. A risk-rating criterion of $\mathrm{RQ}<0.1$, indicating minimal risk to aquatic species, $0.1 \leq \mathrm{RQ} \geq 1$, indicating medium risk, and $\mathrm{RQ}>1$, and indicating high risk, was employed [25].

For estimating the risk of antibiotic resistance, the MEC values and the AF of 1 were utilized. The MIC value for ciprofloxacin was $100 \mathrm{ng} / \mathrm{L}$, whereas the MEC value for tetracycline was $15,000 \mathrm{ng} / \mathrm{L}$, according to Gullberg et al. [26]. As a result, the MIC to produce antibiotic resistance employed in this investigation was $100 \mathrm{ng} / \mathrm{L}$ for all drugs detected in the worst-case scenario.

2.8. Statistical Treatment of Data. Data from the study were analyzed using Origin 2018 (OriginLab Corporation, Northampton, Massachusetts). Values reported in this study are the averages of at least triplicate measurements. Analysis of variance (ANOVA, $\alpha=0.05$ ) was undertaken to test whether the differences between three or more treatment groups are significant, while an independent sample $t$-test $(\alpha=0.05)$ was employed to evaluate two treatment groups.

\section{Results and Discussion}

3.1. Pharmaceutical Compounds in Surface Water. In this study, 8 frequently dispensed pharmaceutically active compounds including 4 antibiotics (amoxicillin, cefuroxime, trimethoprim, and penicillin $\mathrm{V}$ ) and 4 analgesics (tramadol, ibuprofen, acetaminophen, and diazepam) were studied for their presence and levels in surface irrigation water.

Generally, 6 out of the 8 pharmaceutical analytes were detected in the surface water samples. The CEF (44.4\%) recorded the minimum percentage detection, while AMX and IBU recorded $100 \%$ as maximum percentage detection.

Antibiotics were the most prevalent chemicals and the therapeutic group with the overall highest concentration of surface water sample. The individual concentrations of the detected compounds were usually in the tens to hundreds of $\mathrm{ng} / \mathrm{mL}$ range. Concentrations ranged from below detection (n.d) $-840.0 \mathrm{ng} / \mathrm{L}$ for TRIM, 145.0-659.0 $\mathrm{ng} / \mathrm{L}$ for AMX, and n.d-68.0 ng/L for CEF were recorded in this study (Figure 2(a)).

The most concentrated analgesics and anti-inflammatory drugs were acetaminophen, ibuprofen, and diclofenac, with a concentration in the tens to hundreds of $\mathrm{ng} / \mathrm{L}$. 


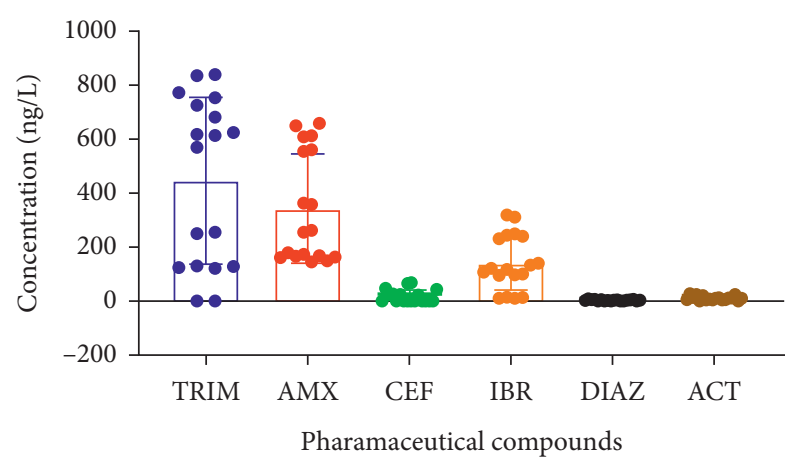

(a)

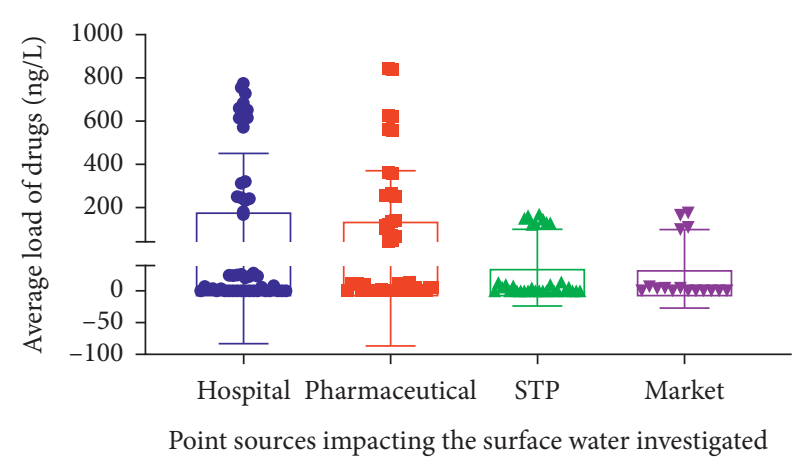

(b)

Figure 2: Scatter plot with error bars of (a) concentration of various pharmaceutical compounds analyzed (b) an average load of pharmaceutical compounds in surface water impacted by various point sources.

Individual concentrations ranged from $10.0-319.0 \mathrm{ng} / \mathrm{L}$ for IBU, n.d - $8.0 \mathrm{ng} / \mathrm{L}$ for DIA, and n.d-27.8 ng/L for PARA (Figure 2(a)). One-way ANOVA revealed a significant difference $(p=0.001)$ among all the pharmaceuticals detected. Considering the huge elimination rates for ibuprofen, acetaminophen, and ketoprofen revealed in wastewater treatment plants $[27,28]$, the high concentrations $[27,28]$, the high concentrations of these compounds in Ghana's surface water could be linked to their widespread use as analgesics and anti-inflammatories in human medicine and the easy access as over-the-counter drugs.

Patterns of pharmaceutical residues in environmental samples may provide clues to their sources and transport pathways, although the association is complicated [27]. Major sources of pharmaceutical residues identified were hospitals followed by pharmaceutical discharges. Sewage treatment plants and drains emanating from the marketplace are a minor source of pharmaceutical residues identified (Figure 2(b)). Large numbers of major hospitals and pharmaceutical companies' wastewater drains are directly discharged into rivers and streams in Ghana. Routinely, wastewater be it partially treated or untreated is released into drains, smaller streams, and other tributaries of larger water bodies, which traditionally serve as irrigation water for many vegetable farmers. The practice of using such water bodies for irrigation has received wide reportage throughout subSaharan Africa, including Ghana [29-31].

The frequency of detection and average concentrations of antibiotics in the surface water sampled were higher than those observed in other Ghanaian rivers [13], and this could be due to the dilution effect in the Ghanaian rivers with high flow.

Since indirect use of polluted water for irrigation is common in Ghana, these high concentrations also suggest an increased risk of uptake by vegetables. Exposure to these pharmaceuticals via the food chain, bioaccumulation, and biomagnification could endanger human and animal health. As a result, even at low concentrations, the negative health and environmental risks linked with exposure to a greater number of pharmaceuticals, their metabolites, and transformed products cannot be overlooked.
Generally, variations of concentration levels were observed due to different sampling campaigns (Figure 3), but they were not to a significant degree of variability. This behavior was observed at both study sites. The concentrations of pharmaceutical residues studied were slightly higher in the dry season samples than in the wet season water. The main factors governing variability in the occurrence of pharmaceuticals in surface water are dilution, flow fluctuations, temperature or UV radiation, degradation processes, and human consumption.

Pearson's correlation revealed positive correlation (Figure 4) among the pharmaceutical analytes that detected with strong and significant correlation occurring between AMX and ACT $(r=0.88, p=0.001), \quad$ AMX and TRIM $(r=0.70$, $p=0.005)$, and IBU and TRIM $(r=0.72, p=0.001)$ (Figure 4$)$.

\subsection{Risk Assessment}

3.2.1. Toxicity. The maximum environmental concentration (MEC) of the studied pharmaceuticals in surface water samples for Daphnids (every species that belongs to the trophic level), fish, and algae PNEC and risk quotients (RQs) is presented in Table 2.

The risk quotients for algae were $9.09 \times 10^{-6}$ to $4.94 \times 10^{-1}$ for all, $5.33 \times 10^{-6}$ to $2.47 \times 10^{-1}$ for daphnids, and $1.78 \times 10^{-6}$ to $1.53 \times 10^{-1}$ for fish (Figure $5(\mathrm{a})$ ).

The RQ values estimated for trimethoprim using the risk-ranking scale [33] were $4.94 E-01$ for algae, $2.47 E-01$ for daphnids, and $1.53 E-01$ for fishes, which indicate a medium risk to all species belonging to their trophic levels. In the aquatic ecosystem, the remaining pharmaceuticals pose little risk to daphnid, fish, and algae. IBP was found to have an RQ of 1.2 in fish by Vazquez-Roig et al. [34], which compared to the RQ of 6.3 reported in this study. Flippin et [35] observed that a month-and-half exposure to low levels of IBP changed the reproduction trend of Japanese Medaka fish. Although there were fewer reproductions, the number of fertilized eggs was higher. IBP and other nonsteroidal anti-inflammatory medicines have been shown to reduce ovulation in mammals, including humans. [25]. 


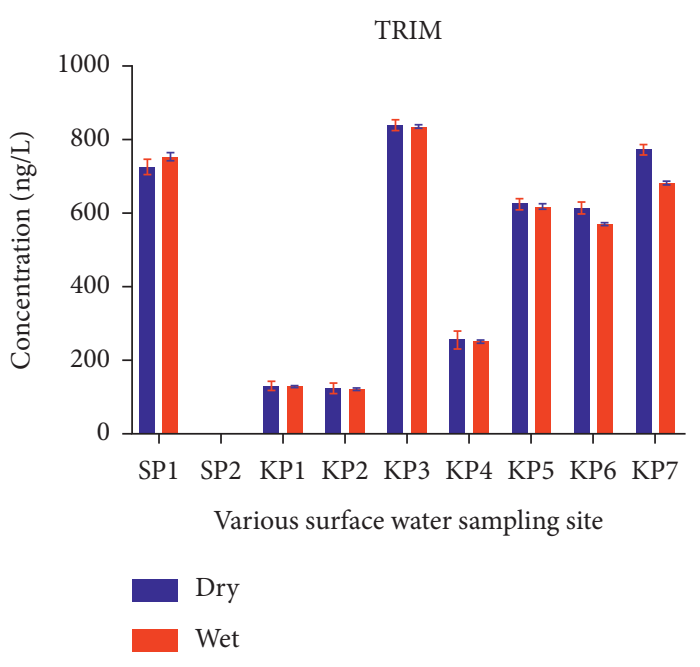

(a)

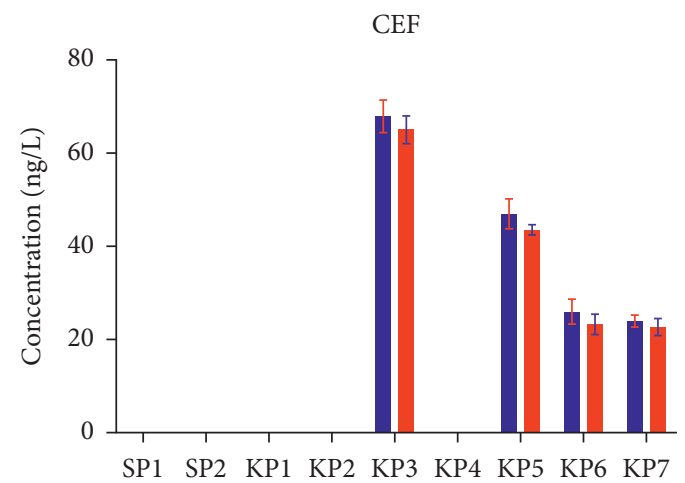

Various surface water sampling site

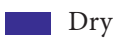

Wet

(c)

DIAZ

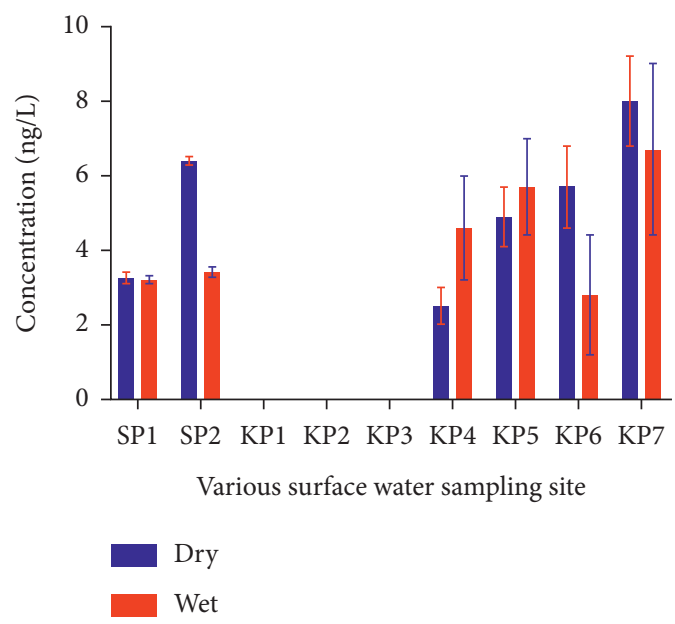

(e)

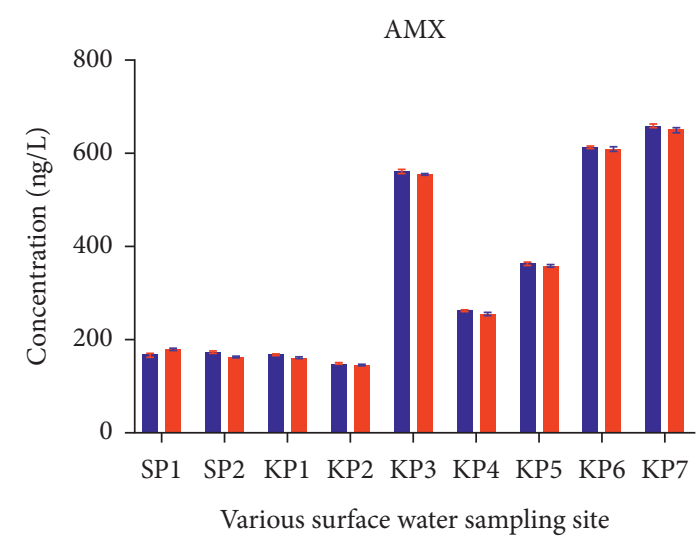

Dry

Wet

(b)

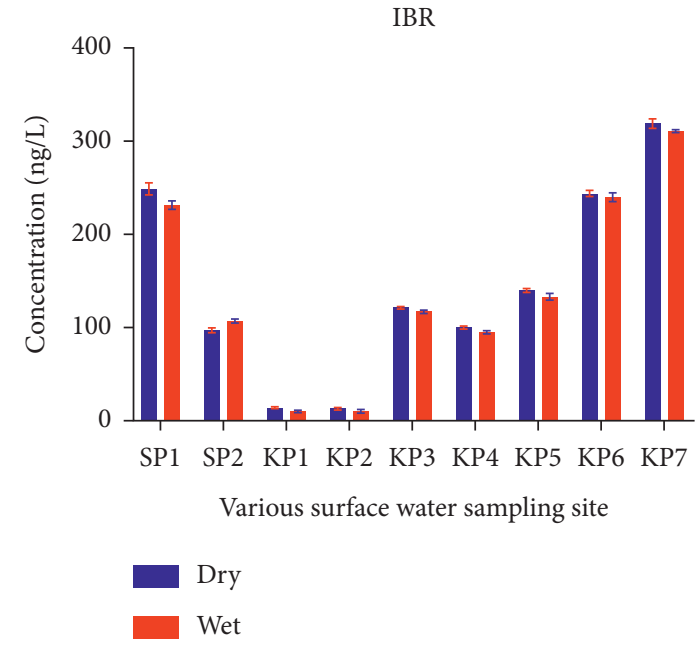

(d)

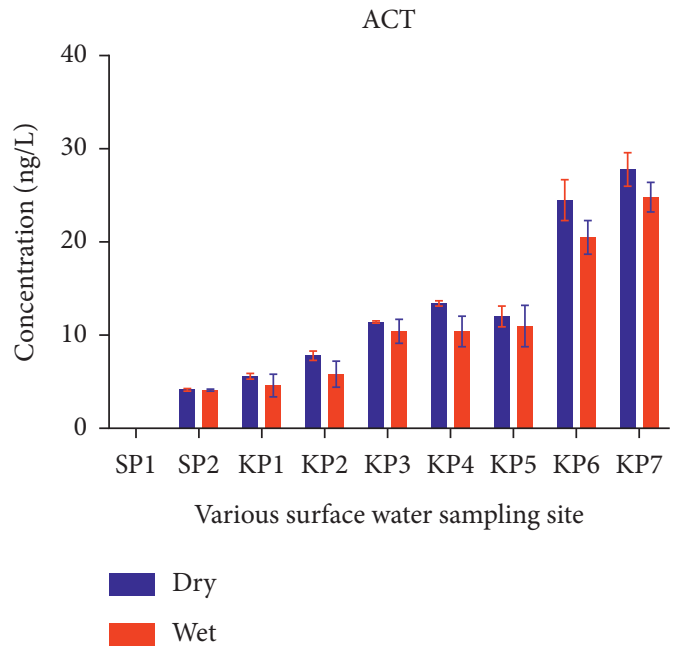

(f)

FIGURE 3: Bar chart showing seasonal variation at various sampling sites for (a) TRIM concentration, (b) AMX concentration, (c) CEF concentration, (d) IBR concentration, (e) DIAZ concentration, and (f) ACT concentration. 


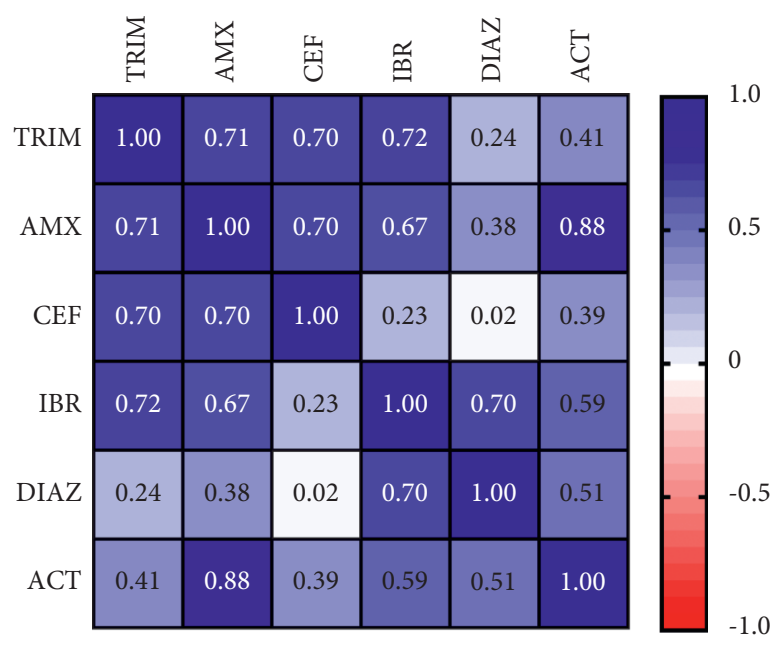

FIgure 4: Chart of Pearson's correlation analysis.

TABLE 2: Toxicity data (PNEC) collected from Ecological Structure -Activity Relationships (ECOSAR) model [32]. Ecological StructureActivity Relationships (ECOSAR) Model Class Program. US EPA/OPPT, USA.

\begin{tabular}{|c|c|c|c|c|c|c|c|}
\hline Antibiotics & $\operatorname{MEC}(\mu \mathrm{g} / \mathrm{L})$ & PNEC algae $(\mu \mathrm{g} / \mathrm{L})$ & RQ algae & PNEC daphnid $(\mu \mathrm{g} / \mathrm{L})$ & RQ daphnid & PNEC fishes $(\mu \mathrm{g} / \mathrm{L})$ & RQ fishes \\
\hline TRIM & $8.40 E+02$ & $1.70 E+03$ & $4.94 E-01$ & $3.40 E+03$ & $2.47 E-01$ & $5.50 E+03$ & $1.53 E-01$ \\
\hline AMX & $6.59 E+02$ & $1.00 E+04$ & $6.59 E-02$ & & & $2.50 E+04$ & $2.64 E-02$ \\
\hline $\mathrm{CEF}$ & $6.80 E+01$ & $4.20 E+04$ & $1.62 E-03$ & $4.60 E+04$ & $1.48 E-03$ & $1.20 E+05$ & $5.67 E-04$ \\
\hline
\end{tabular}

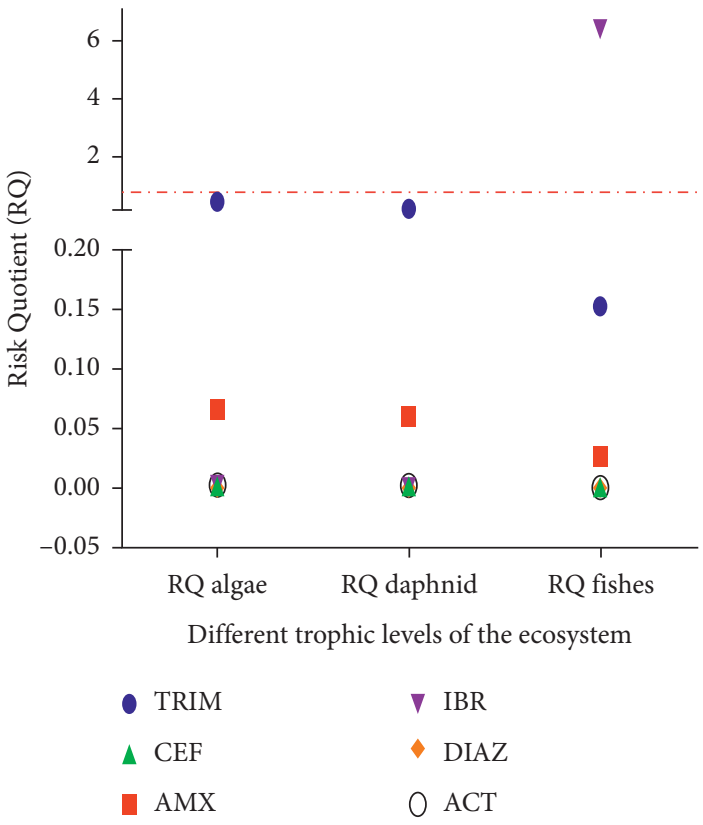

(a)

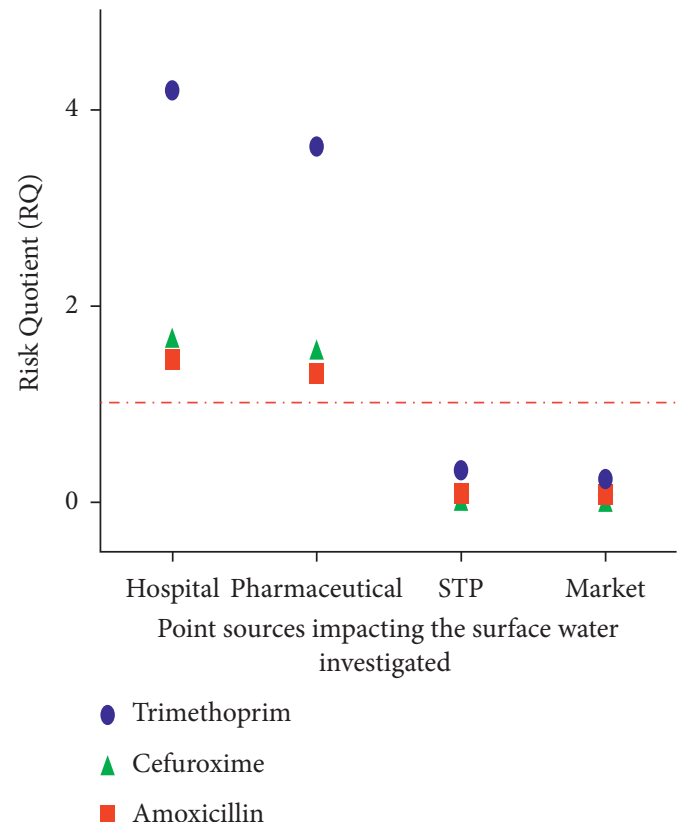

(b)

FIGURE 5: Estimated risk quotient (RQ) for (a) toxicity among different trophic levels in the ecosystem and (b) antibiotic resistance of various point sources impacting the surface water investigated.

This risk assessment includes flaws, which include paucity of long-term research on toxicology and the impossibility of conducting chronic investigations throughout the organism's existence (especially in fishes). Antibiotics in the environment, on the other hand, are a problem that not only affects the ecosystem but also antibiotic resistance.

Pharmaceuticals analyzed in this study are readily detected in the environment in view of their easy access over the counter that does not require any medical prescription, 
which allows for self-medication in developing countries like Ghana [36]. These are found in the tens to hundreds of $\mathrm{ng} / \mathrm{L}$ range. Through food quality, these concentrations may have an impact on the ecosystem and human health. Surface water is used for water contact activities such as drinking and food preparation in developing countries like Ghana [37]. Consequently, intake of these surface waters could expose people to antibiotic levels below the sub-MIC, which according to Gullberg et al. [26] have the potential to cause antibiotic resistance development. In Kenya, ibuprofen concentration as high as $30,000 \mathrm{ng} / \mathrm{L}$ was detected in sewage treatment plant effluent entering rivers [38], which is a thousand times higher than maximum concentrations of ibuprofen in sewage treatment plant effluent entering rivers in this study $(14 \mathrm{ng} / \mathrm{L})$. This could partly be due to relatively efficient sewage treatment facilities in Ghana [19], which decreases the pollution levels of STPs to surface water. Generally, the different consumption rates, sampling times, and seasonal effects could explain the significant variations of concentration levels observed across different STPs.

Tagoe and Attah [39] asserted that antibiotics of the $\beta$-lactam class, notably amoxicillin, are the most commonly prescribed in Ghana. This is followed by ampicillin and cefuroxime. This study agreed with the findings of Tagoe and Attah, with the maximum concentration of amoxicillin being $179.2 \mathrm{ng} / \mathrm{L}$ while that of cefuroxime was $47.0 \mathrm{ng} / \mathrm{L}$. This trend appears different from the study by Azanu et al. [13] which reported cefuroxime and amoxicillin concentrations as high as 65 and $1.3 \mathrm{ng} / \mathrm{L}$, respectively, for surface water used for irrigation. However, trimethoprim concentrations in the surface water reported in this study were comparable with a similar study performed by Azanu et al. [13].

Kümmerer and Henninger [40] calculated the PNEC concentration of amoxicillin to be $3.7 \mathrm{ng} / \mathrm{L}$. The highest concentration obtained in this investigation was higher than the PNEC, indicating that bacteria in the sewage treatment facility may have an undesirable effect. There is a need for more research to determine their impact.

3.2.2. Antibiotics Resistance. According to Gullberg et al. [26], the estimated risk quotient for antibiotic resistance development for trimethoprim, $0.02-1.46$ for amoxicillin, and $0.01-1.68$ for cefuroxime was $0.24-4.20$ (Figure 5(b)).

The RQ values were above 1 for all the antibiotics investigated in surface water impacted by hospitals and pharmaceutical companies' wastewater. However, for all antibiotics investigated in surface water impacted by STPs and market wastewater, the RQ values were below 1 . Gullberg et al. [26] found that MIC for the development of antibiotic resistance for ciprofloxacin and tetracycline is $100 \mathrm{ng} / \mathrm{L}$ and $15 \mathrm{~g} / \mathrm{L}$, respectively. This implies that there is a medium to high risk of antibiotic resistance development in the study area. The sub-MIC selective window is much larger than the classic selective window because antibiotic doses hundreds of times lower than the susceptible strains' MIC can select resistant bacteria [41]. To determine the level of exposure and the danger involved, more research would be required. There is the need to assess the risk of food contamination, since point sources of emerging pollutants like antibiotics and analgesics monitored in this study are directly discharged into streams and rivers without treatment. Surface water used for agricultural purposes such as vegetable cultivation is rampant in Ghana, while several studies have proved that pharmaceuticals could be absorbed by plants [13]. The accumulation of pharmaceuticals in foodstuffs in the study areas would expose consumers to drug resistance development.

\section{Conclusions}

The findings of this study confirmed the presence of amoxicillin, trimethoprim, diazepam, ibuprofen, and acetaminophen, while tramadol, cefuroxime, and penicillin $\mathrm{V}$ were undetected in the surface water for vegetable irrigation in Sunyani.

Analgesics such as acetaminophen, ibuprofen, and diclofenac and antibiotics including amoxicillin, trimethoprim, and cefuroxime were found in this study. These pharmaceutical concentrations range from tens to hundreds of $\mathrm{ng} / \mathrm{L}$. Analgesics showed concentrations of up to $319.0 \mathrm{ng} / \mathrm{L}$ while the antibiotics up to $840.0 \mathrm{ng} / \mathrm{L}$. The widespread usage of analgesics and anti-inflammatory in Ghana, as most of them are easily obtained as an over-thecounter drug, could explain the high concentrations of these substances in the surface water. The point source of pharmaceutical residues entering into the surface water studied was in decreasing order as follows: hospital > pharmaceutical companies $>$ sewage treatment plants $>$ wastewater from market.

Based on the availability of long-term data, an environmental risk assessment was conducted. Because of the presence of ibuprofen, the results revealed that the lowest trophic level and fish are at risk. The estimated risk quotient values for antibiotic resistance were above 1 for all the antibiotics studied in surface water greatly influenced by hospitals and pharmaceutical companies' wastewater except surface water impacted by sewage treatment plants (STPs) and market wastewater. The existence of pharmaceuticals in the environment is not solely a worry for the environment but also a human health threat in Ghana given the attending impact on drinking water and vegetable production.

\section{Data Availability}

All the data supporting the findings of this publication have been incorporated into the manuscript.

\section{Conflicts of Interest}

The authors attest that there are no conflicts of interest in respect of this publication.

\section{Authors' Contributions}

David Adu-Poku contributed conceptualized the study, supervised the study, developed the methodology, provided the resources, performed investigation, and wrote the 
manuscript. David Azanu conceptualized the study, developed the methodology, provided the resources, performed investigation, and wrote the manuscript. Selina Saah conceptualized the study, supervised the study, developed the methodology, provided the resources, contributed to project administration, and wrote the manuscript. William Ofori Appaw conceptualized the study, developed the methodology, provided the resources, and performed investigation. All the authors have agreed and given approval for the publication of this manuscript.

\section{Acknowledgments}

Killian Asosega, Franklin Nyarko, Frank Selorm Awumey, Christina Lovely-Quao, Adom Cletus Fosu, Adu Fosu Emmanuel, Wisdom Sefenu Kwabla, Edward Aboagye, Sarah Newman, Bernice Gyasi, and Julius Agongo are acknowledged for the various assistance they offered for this research.

\section{References}

[1] World Health Organization, Global Antimicrobial Resistance and Use Surveillance System (GLASS) Report, World Health Organization, Geneva, Switzerland, 2020.

[2] S. Mölstad, M. Erntell, H. Hanberger et al., "Sustained reduction of antibiotic use and low bacterial resistance: 10-year follow-up of the Swedish Strama programme," The Lancet Infectious Diseases, vol. 8, no. Issue 2, pp. 125-132, 2008.

[3] S. Mölstad, S. Löfmark, K. Carlin et al., "Lessons learned during 20 years of the Swedish strategic programme against antibiotic resistance," Bulletin of the World Health Organization, vol. 95, no. 11, pp. 764-773, 2017.

[4] S. W. Olesen, M. L. Barnett, D. R. MacFadden et al., "The distribution of antibiotic use and its association with antibiotic resistance," ELife, vol. 7, 2018.

[5] P. Yang, Y. Chen, S. Jiang, P. Shen, X. Lu, and Y. Xiao, "Association between antibiotic consumption and the rate of carbapenem-resistant Gram-negative bacteria from China based on 153 tertiary hospitals data in 2014," Antimicrobial Resistance and Infection Control, vol. 7, no. 1, pp. 1-7, 2018.

[6] E. Y. Klein, T. P. Van Boeckel, E. M. Martinez et al., "Global increase and geographic convergence in antibiotic consumption between 2000 and 2015," Proceedings of the National Academy of Sciences of the United States of America, vol. 115, no. 15, pp. E3463-E3470, 2018.

[7] L. Charuaud, E. Jardé, A. Jaffrézic et al., "Veterinary pharmaceutical residues in water resources and tap water in an intensive husbandry area in France," The Science of the Total Environment, vol. 664, pp. 605-615, 2019.

[8] I. Krizman-Matasic, P. Kostanjevecki, M. Ahel, and S. Terzic, "Simultaneous analysis of opioid analgesics and their metabolites in municipal wastewaters and river water by liquid chromatography-tandem mass spectrometry," Journal of Chromatography A, vol. 1533, pp. 102-111, 2018.

[9] K. S. Le Corre, C. Ort, D. Kateley, B. Allen, B. I. Escher, and J. Keller, "Consumption-based approach for assessing the contribution of hospitals towards a load of pharmaceutical residues in municipal wastewater," Environment International, vol. 45, pp. 99-111, 2012.

[10] A. Küster and N. Adler, "Pharmaceuticals in the environment: scientific evidence of risks and its regulation," Philosophical
Transactions of the Royal Society B: Biological Sciences, vol. 369, no. 1656, Article ID 20130587, 2014.

[11] A. Suchomel, H. Goeden, and J. Dady, "A method for developing rapid screening values for active pharmaceutical ingredients (APIs) in water and results of initial application for 119 APIs," International Journal of Environmental Research and Public Health, vol. 15, no. 7, 2018.

[12] Ho W. Leung, L. Jin, S. Wei et al., "Pharmaceuticals in tap water: human health risk assessment and proposed monitoring framework in China," Environmental Health Perspectives, vol. 121, no. 7, pp. 839-846, 2013.

[13] D. Azanu, C. Mortey, G. Darko, J. J. Weisser, B. Styrishave, and R. C. Abaidoo, "Uptake of Antibiotics from irrigation water by plants," Chemosphere, vol. 157, pp. 107-114, 2016.

[14] BIO Intelligence Service, Study on the Environmental Risks of Medicinal Products, p. 310, Final Report prepared for Executive Agency for Health and Consumers, Copenhagen, Denmark, 2013.

[15] World Health Organization, Resource Mobilisation for Antimicrobial Resistance (AMR): Getting AMR into Plans and Budgets of Government and Development Partners Nepal Country-Level Report, World Health Organization, Geneva, Switzerland, 2018.

[16] S. K. Yevutsey, K. O. Buabeng, M. Aikins et al., "Situational analysis of antibiotic use and resistance in Ghana: policy and regulation," BMC Public Health, vol. 17, no. 1, 2017.

[17] A. M. Lerbech, J. A. Opintan, S. O. Bekoe et al., "Antibiotic exposure in a low-income country: screening urine samples for presence of antibiotics and antibiotic resistance in coagulase negative staphylococcal contaminants," PLoS One, vol. 9, Article ID e113055, 2014.

[18] M. B. M. Ahmed, A. U. Rajapaksha, J. E. Lim et al., "Distribution and accumulative pattern of tetracyclines and sulfonamides in edible vegetables of cucumber, tomato, and lettuce," Journal of Agricultural and Food Chemistry, vol. 63, no. 2, pp. 398-405, 2015.

[19] D. Azanu, B. Styrishave, G. Darko, J. J. Weisser, and R. C. Abaidoo, "Occurrence and risk assessment of antibiotics in water and lettuce in Ghana," The Science of the Total Environment, vol. 622-623, no. December, pp. 293-305, 2018.

[20] World Health Organization, Pharmaceuticals in Drinking Water, World Health Organization, Geneva, Switzerland, 2012.

[21] T. Backhaus, "Medicines, shaken and stirred: a critical review on the ecotoxicology of pharmaceutical mixtures," Philosophical Transactions of the Royal Society B: Biological Sciences, vol. 369, no. 1656, Article ID 20130585, 2014.

[22] A. Shraim, A. Diab, A. Alsuhaimi et al., "Analysis of some pharmaceuticals in municipal wastewater of Almadinah Almunawarah," Arabian Journal of Chemistry, vol. 10, pp. S719-S729, 2017.

[23] EMEA, Guideline On the Environmental Risk Assessment of Medicinal Products for Human Use, EMEA, Scherpenzeel, The Netherlands, 2006.

[24] H. W. Leung, T. B. Minh, M. B. Murphy et al., "Distribution, fate and risk assessment of antibiotics in sewage treatment plants in Hong Kong, South China," Environment International, vol. 42, pp. 1-9, 2012.

[25] M. Hernando, M. Mezcua, A. Fernandezalba, and D. Barcelo, "Environmental risk assessment of pharmaceutical residues in wastewater effluents, surface waters and sediments," Talanta, vol. 69, no. 2, pp. 334-342, 2006. 
[26] E. Gullberg, S. Cao, O. G. Berg et al., "Selection of resistant bacteria at very low antibiotic concentrations," PLoS Pathogens, vol. 7, no. 7, Article ID e1002158, 2011.

[27] A. Jelic, M. Gros, A. Ginebreda, R. Cespedes-Sánchez, F. Ventura, and M. Petrovic, "Occurrence, partition, and removal of pharmaceuticals in sewage water and sludge during wastewater treatment," Water Resources, vol. 45, no. 3, pp. 1165-1176, 2011.

[28] K. M. Onesios, J. T. Yu, and E. J. Bower, "Biodegradation and removal of pharmaceuticals and personal care products in treatment systems: a review," Biodegradation, vol. 20, pp. 441-466, 2009.

[29] G. A. Cornish and J. B. Aidoo, "Informal irrigation in the Periurban zone of Kumasi, Ghana," in Findings from an initial questionnaire surveyHR Wallingford, Wallingford, UK, 2000.

[30] P. Drechsel and B. Keraita, Irrigated Urban Vegetable Production in Ghana: Characteristics, Benefits and Risk Mitigation, pp. 1-249, International Water Management Institute, Anand, India, 2014.

[31] B. Keraita, B. Jimenez, and P. Drechsel, "Extent and implications of agricultural reuse of untreated, partly treated, and diluted wastewater in developing countries," CAB Reviews: Perspectives in Agriculture, Veterinary Science, Nutrition and Natural Resources, vol. 3, no. 58, pp. 1-15, 2008.

[32] US-EPA, Ecological Structure-Activity Relationship Model (ECOSAR) Class Program, K. Mayo-Bean, K. Moran, B. Meylan, and P. Ranslow, Eds., US EPA/OPPT, Washington, DC, USA, 2012.

[33] A. P. Hernandez, C. Graham, L. L. Master, and D. L. Albert, "The effect of sample size and species characteristics on performance of different species distribution modeling methods," Ecography, vol. 29, no. 5, pp. 773-785, 2006.

[34] P. Vazquez-Roig, V. Andreu, C. Blasco, and Y. Picó, "Risk assessment on the presence of pharmaceuticals in sediments, soils, and waters of the Pego-Oliva Marshlands (Valencia, Eastern Spain)," The Science of the Total Environment, vol. 440, pp. 24-32, 2012.

[35] J. L. Flippin, D. Huggett, and C. M. Foran, "Changes in the timing of reproduction following exposure to ibuprofen in Japanese Medaka, Oryzias latipes," Aquatic Toxicology, vol. 81, no. 1, pp. 73-78, 2007.

[36] M. Manrique-Moreno, L. Heinbockel, M. Suwalsky, P. Garidel, and K. Brandenburg, "Biophysical study of the non-steroidal ant-inflammatory drugs (NSAID) Ibuprofen, naproxen and diclofenac with phosphatidylserine bilayer membranes," Biochimica et Biophysica Act (BBA)-Biomembranes, vol. 1858, no. 9, pp. 2123-2131, 2016.

[37] K. Obiri-Danso and K. Jones, "Aspects of health-related microbiology of the Subin, an urban river in Kumasi, Ghana," Journal of Water and Health, vol. 3, no. 1, pp. 69-76, 2005.

[38] K. O. Koreje, K. Demeestere, P. De Wispelaere, L. Vergeynst, J. Dewulf, and H. V. Langenhove, "From multi-residue screening to target analysis of pharmaceuticals in water: development of a new approach based on magnetic sector mass spectrometry and application in the Nairobi River basin, Kenya," Science of the Total Environment, vol. 437, pp. 153164, 2012.

[39] D. Tagoe and C. Attah, "A study of antibiotic use and abuse in Ghana: a case study of the cape coast metropolis," The Internet Journal of Health, vol. 11, no. 2, pp. 1-6, 2010.

[40] K. Kümmerer and A. Henninger, "Promoting resistance by the emission of antibiotics from hospitals and households into the effluent," Clinical Microbiology and Infections, vol. 9, pp. 1203-1214, 2003.
[41] D. I. Andersson and D. Hughes, "Microbiological effects of sublethal levels of antibiotics," Nature Reviews Microbiology, vol. 12, no. 7, pp. 465-478, 2014. 